\title{
ESCOAMENTO SUPERFICIAL NA INTERAÇÃO: COBERTURA VEGETAL E PRÁTICAS DE CONTROLE DE EROSÃO
}

\author{
MARCO A. R. DE CARVALHO ${ }^{1}$, JARBAS H. DE MIRANDA ${ }^{2}$, SERGIO N. DUARTE ${ }^{3}$, \\ LILIAN C. C. DE CARVALHO ${ }^{4}$
}

RESUMO: O escoamento da água oriunda das terras agricultadas é o principal fator poluente dos mananciais hídricos nas áreas rurais. Devido a esse fato, faz-se necessário o desenvolvimento e a aplicação de tecnologias que venham a reduzir descargas de resíduos indesejáveis. Nesse sentido, conduziu-se um experimento na área experimental do Departamento de Engenharia Rural ESALQ/USP, Piracicaba - SP, com o objetivo de avaliar o efeito de diferentes condições de solo, (feijão, gramínea e solo nu) e diferentes práticas de controle de erosão (sulco de infiltração, terraço de infiltração e sem práticas de controle de erosão), buscando-se estimar o escoamento superficial. $\mathrm{O}$ delineamento estatístico adotado foi o em blocos aleatorizados, em esquema fatorial $3 \times 3$, perfazendo 9 tratamentos com 3 repetições. O período de coleta de dados pluviométricos foi de 06 de dezembro de 2007 a 11 de abril de 2008; para isto, utilizou-se de um pluviômetro, com $21,1 \mathrm{~cm}$ de diâmetro, instalado na área experimental. Observando-se as perdas de água, em relação às estruturas, tem-se em ordem decrescente de eficiência: Terraço, Sulco e Rampa; e com relação às coberturas, tem-se em ordem decrescente de eficiência: Feijão, Capim e Solo Nu.

PALAVRAS-CHAVE: terraço de infiltração, "mulching” vertical, cobertura vegetal.

\section{EROSION LOSSES FROM RUNOFF: INTERACTION OF SOIL COVER AND EROSION CONTROL PRACTICE}

\begin{abstract}
The flow of sediment from cropped land is the main pollutant of water sources in rural areas. Due to this fact, it is necessary to develop and implement technologies that will reduce water and sediment discharges. Accordingly, an experiment was conducted in the Department of Biosystems Engineering - ESALQ / USP, Piracicaba - SP with the objective to evaluate the effect of different soil cover (bean, grass and bare ground) and erosion control practices (wide base terraces and infiltration furrows in slopes (no practices to control erosion)) while measuring water losses in runoff. The statistical design adopted was randomized blocks in a $3 \times 3$ factorial scheme resulting in 9 treatments with 3 replicates (blocks). The period of rainfall data collection was December 6, 2007 to April 11, 2008. A $21.1 \mathrm{~cm}$ diameter rain gauge was installed in the experimental area. Terraces were the most efficient practices for reducing erosion losses in the treatments with infiltration furrows being better than the control treatment. Bean was more effective than grass in reducing erosion. Bare ground was the least efficient.
\end{abstract}

KEYWORDS: infiltration terrace, vertical mulching, soil covering.

\footnotetext{
${ }^{1}$ Professor do Instituto Federal do Ceará - Campus Sobral.

${ }^{2}$ Prof. Associado 2, Depto. Engenharia de Biossistemas, Escola Superior de Agricultura "Luiz de Queiroz" - ESALQ/USP jhmirand@usp.br.

${ }^{3}$ Prof. Associado 2 - Departamento de Engenharia de Biossistemas - ESALQ/USP, Piracicaba - SP; snduarte@usp.br.

${ }^{4}$ Professora do Instituto Federal do Ceará - Campus Sobral.

Recebido pelo Conselho Editorial em: 30-7-2010

Aprovado pelo Conselho Editorial em: 2-7-2012
} 


\section{INTRODUÇÃO}

As terras erosionadas reduzem a capacidade de produção e, sendo assim, pode-se dizer que a erosão do solo apresenta, de certa forma, uma relação direta com a escassez de alimentos. Por isso, em algumas regiões do mundo, o controle da erosão passa a ser fundamental.

A erosão tende a elevar os custos de produção dos produtos agropecuários, uma vez que se aumenta a necessidade de uso de corretivos e fertilizantes, e reduz-se a eficiência operacional das máquinas, além dos custos adicionais com as próprias práticas para controle da erosão.

Diante desses aspectos, pode-se dizer que a sustentabilidade dos sistemas agrícolas está diretamente relacionada ao manejo do solo e das culturas, e seu princípio está baseado na manutenção e melhoria da estrutura do solo, aumentando-se a taxa de infiltração de água e reduzindo-se o escoamento superficial.

Segundo SANTOS et al. (2010), precipitações pluviométricas de maior intensidade e com grande frequência elevam o risco de ocorrência da erosão. Essas características são mais significativas quando associadas às condições de relevo, características físico-hídricas do solo, uso e manejo inadequados.

Taxa de infiltração é definida por LIBARDI et al. (2005) como sendo a quantidade de água que atravessa a unidade de área da superfície do solo por unidade de tempo, e a capacidade de infiltração de um solo é um valor final e constante de taxa de infiltração que se estabilizou com o passar do tempo.

Com a manutenção dos resíduos vegetais na superfície do solo, esses poderão interceptar as gotas de chuva e dissipar sua energia, evitando a desagregação das partículas e a formação do selamento superficial (MARTINS FILHO et al., 2009).

O manejo adequado do solo deve englobar um conjunto de práticas agrícolas que proporcionem máxima retenção da água das chuvas, adaptem a velocidade de infiltração de água no solo, reduzam a velocidade de escoamento da água, aumentem a capacidade de armazenamento de água no solo e proporcionem boas condições físicas e químicas no solo para o desenvolvimento das culturas.

A determinação da erosividade da chuva envolve um trabalho exaustivo de seleção e leitura de uma série de registros de chuvas, sendo esses dados escassos e, muitas vezes, de difícil acesso (MELLO et al., 2007). Tal fato faz com que informações relativas à erosividade estejam disponíveis apenas para pequeno número de localidades no Brasil (MOREIRA et al., 2006).

O solo desprovido da cobertura vegetal e da ação fixadora das raízes, exposto ao impacto direto das gotas de chuva, sofre desagregação, efeito que é complementado pela energia do escoamento superficial das águas, causando elevadas perdas de solo (SILVEIRA, 1998).

Portanto, devido ao grande interesse em se quantificar e minimizar o escoamento superficial, tendo em vista a preocupação com impactos ambientais para gerações futuras, objetivou-se com este trabalho avaliar o efeito de diferentes coberturas de solo, aliados a terraços de base larga e sulcos de infiltração, em rampas, buscando-se estimar as perdas de água por escoamento superficial.

\section{MATERIAL E MÉTODOS}

O experimento foi conduzido na Área Experimental de Irrigação e Drenagem do Departamento de Engenharia Rural, pertencente à Escola Superior de Agricultura "Luiz de Queiroz" - ESALQ, Universidade de São Paulo - USP, localizada no município de Piracicaba - SP, que tem como coordenadas $22^{\circ} 42^{\prime} 30^{\prime}$ " de latitude sul e $47^{\circ} 30^{\prime} 00^{\prime}$ " de longitude oeste e altitude de $576 \mathrm{~m}$. O solo é classificado como Nitossolo Vermelho eutrófico ("Série Luiz de Queiroz"), de textura argilosa, com declividade média de 9,2\%.

As atividades de instalação ocorreram de setembro a novembro de 2007, nas quais foram 
realizadas as etapas de campo; primeiro com o preparo inicial do solo, onde foi feita uma gradagem por intermédio de grade de discos e serviço de terraplanagem por meio de lâmina frontal.

As 27 parcelas experimentais foram montadas diretamente no campo, sendo 3 blocos com 9 parcelas, cada uma medindo $12 \mathrm{~m}$ de comprimento por $1,5 \mathrm{~m}$ de largura, sendo o comprimento da parcela no sentido de maior declividade do terreno (Figura 1).

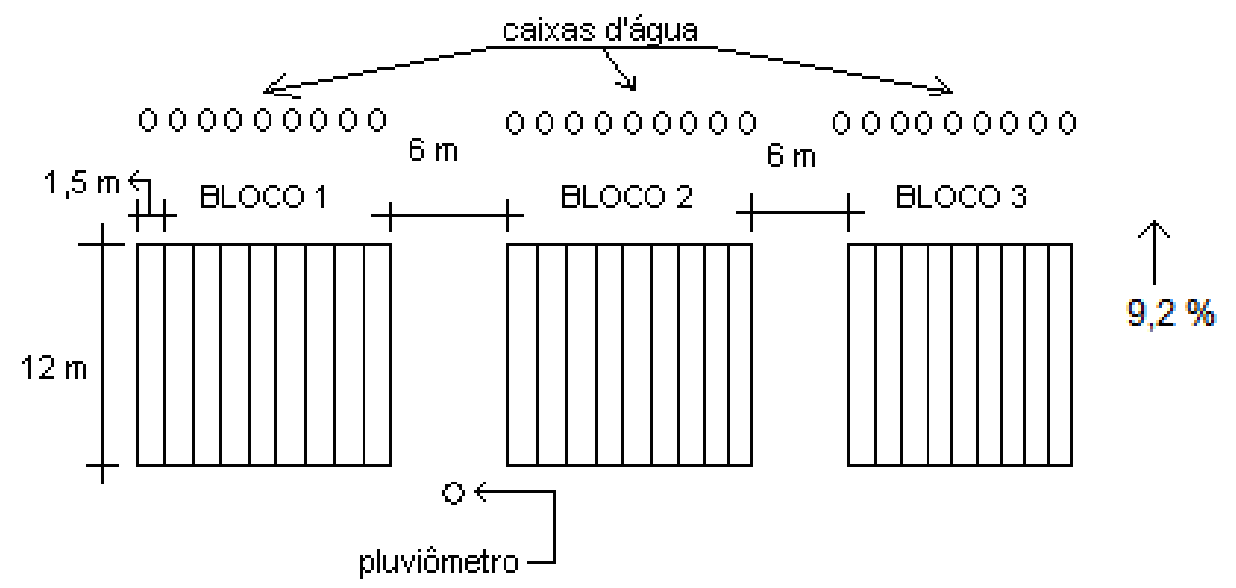

FIGURA 1. Croqui da área experimental. Experimental area.

Após a definição das parcelas experimentais, foi realizada a acomodação das caixas d'água, sendo as 27 caixas d'água de 500 litros niveladas em terreno de chão batido, com desnível aproximado de 1 metro em relação à área das parcelas.

A conexão do final da parcela à caixa d'água foi feita com tubos de $\mathrm{PVC}$ de 2 polegadas, para levar por gravidade o escoamento superficial gerado na parcela, através de um furo na lona e vedação por fita adesiva do tipo "silver tape".

Esta fase do experimento finalizou-se com a construção das estruturas de contenção de enxurradas (terraços e sulcos de infiltração) e instalação do pluviômetro na área experimental.

Os terraços foram construídos no meio da parcela (6 $\mathrm{m}$ da saída), com uma profundidade de sulco de $10 \mathrm{~cm}$, largura de sulco de $70 \mathrm{~cm}$ e altura de camalhão de $20 \mathrm{~cm}$ em relação ao fundo do sulco.Os sulcos de infiltração também foram instalados no meio da rampa, com uma profundidade de $30 \mathrm{~cm}$, largura de $20 \mathrm{~cm}$ e preenchidos com bagaço de cana.

O delineamento estatístico adotado no experimento foi o de blocos aleatorizados, em esquema fatorial 3x3 (estruturas de contenção de enxurradas x cobertura do solo), perfazendo 9 tratamentos, com 3 repetições, sendo considerado cada bloco uma repetição. As estruturas de contenção de enxurrada foram: sulco de infiltração, terraço de infiltração e rampa (sem estrutura de contenção), e as coberturas do solo foram: feijão, capim e solo nu (ausência de cobertura vegetal no solo).

As declividades dos blocos 1, 2 e 3 foram, respectivamente: 8,6\%; 8,9\% e 10,0\%.

As análises estatísticas foram realizadas de acordo com os critérios estabelecidos por GOMES (1990). Nessas análises, foram utilizadas planilhas do EXCEL, na análise da variância, e os tratamentos foram comparados pelo teste $\mathrm{F}$, considerando-se um nível mínimo de significância de $1 \%$ de probabilidade. As comparações entre médias foram realizadas pelo teste de Tukey, aos níveis de $5 \%$ de probabilidade.

Durante o período de dezembro de 2007 a abril de 2008, foram feitos trabalhos de medição da precipitação pluviométrica e leitura das lâminas acumuladas nas caixas d'água logo após o término da chuva (Figura 2). Em seguida, era realizada a limpeza das 27 caixas d'água para a viabilidade da leitura seguinte. 


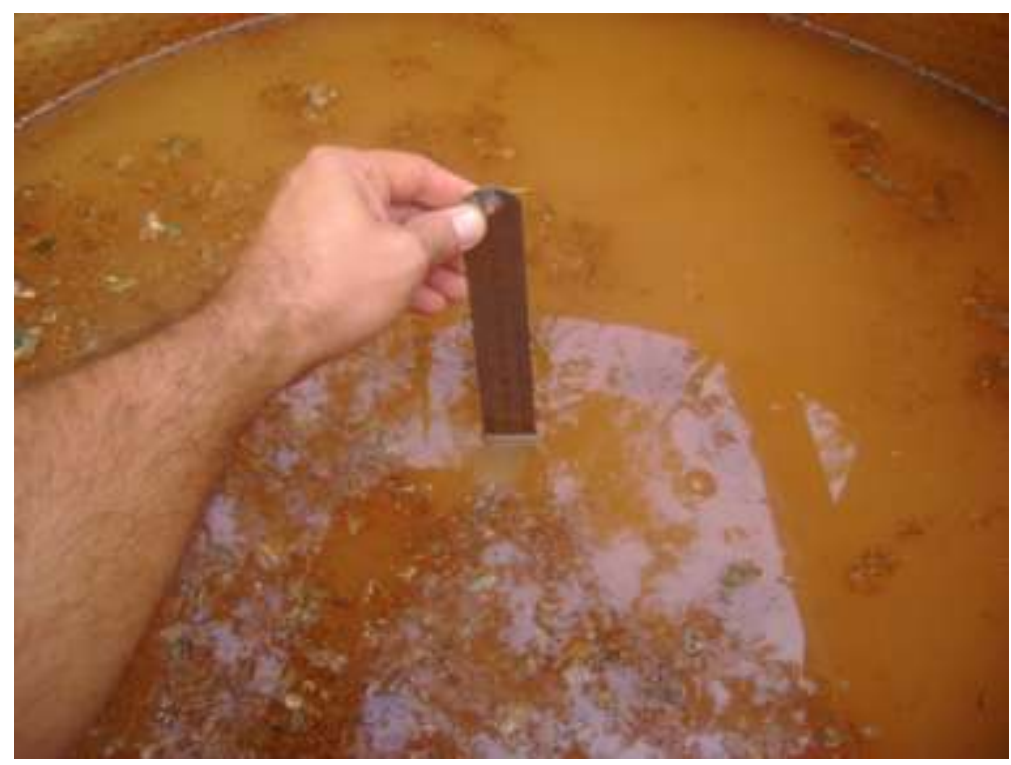

FIGURA 2. Leitura da lâmina escoada. Measurement of runoff depth.

Do dia 11 ao dia 15 de dezembro de 2007, foi realizado a semeadura do feijão nos 3 blocos, a uma profundidade em torno de $3 \mathrm{~cm}$, com fileiras espaçadas $50 \mathrm{~cm}$ entre si, em curvas de nível, com 18 plantas a cada parcela, simulando, assim, a semeadura.

Entre os dias 18 e 20 de dezembro de 2007, foi realizada a semeadura do capim com auxílio do enxadão, sendo cavados sulcos a $50 \mathrm{~cm}$ de distância entre si, com $2 \mathrm{~cm}$ de profundidade, em curvas de nível. Após um veranico de 12 dias, entre os dias 21 de dezembro de 2007 e 2 de janeiro de 2008, ocorreu uma precipitação de (91,4 mm, sendo 72,5 mm em $2 \mathrm{~h}$ e $45 \mathrm{~min}$ ), sendo as plantas de feijão ( 2 semanas após emergência) danificadas e comprometidas em torno de $80 \%$, o que levou à necessidade de um replantio total das parcelas de feijão, que aconteceu entre os dias 5 e 10 de janeiro de 2008. Os danos causados nas parcelas com capim por esta mesma chuva foram mínimos, não havendo, assim, a necessidade de serem replantadas.

O controle de ervas invasoras dentro das parcelas foi feito manualmente, sempre que necessário. A calagem e as adubações não foram necessárias, conforme análise química do solo, pois os valores presentes estavam dentro da média para uma boa produção, e a intenção do trabalho era revolver o solo o mínimo possível (Tabela 1).

TABELA 1. Análise química do solo da área experimental. Soil chemical analysis of the experimental area.

\begin{tabular}{|c|c|c|c|c|c|c|c|c|c|c|c|}
\hline $\begin{array}{c}\mathrm{pH} \\
\mathrm{CaCl}_{2}\end{array}$ & $\begin{array}{l}\text { M.O. } \\
\mathrm{g} \mathrm{dm}^{-3}\end{array}$ & $\begin{array}{c}\mathrm{P} \\
\mathrm{mg} \mathrm{dm}^{-3}\end{array}$ & K & $\mathrm{Ca}$ & $\mathrm{Mg}$ & $\begin{array}{c}\mathrm{H}+\mathrm{Al} \\
\text { mmolc dr }\end{array}$ & $\begin{array}{l}\mathrm{Al} \\
3\end{array}$ & S.B. & CTC & $\begin{array}{l}\text { Sat.b } \\
\text { V\% }\end{array}$ & $\begin{array}{c}\text { Sat.Al } \\
\%\end{array}$ \\
\hline 5,0 & 30 & 5 & 4,2 & 28 & 12 & 31 & 0 & 44 & 75 & 59 & 0 \\
\hline
\end{tabular}

Foram coletadas amostras de solo na profundidade de 0 a $0,20 \mathrm{~m}$, para a obtenção das características físicas do solo, apresentadas na Tabela 2.

TABELA 2. Características físicas do solo da área experimental. Soil physical characteristics of the experimental área.

\begin{tabular}{|c|c|c|c|c|c|}
\hline \multicolumn{3}{|c|}{ GRANULOMETRIA (\%) } & \multirow{2}{*}{$\begin{array}{c}\text { CLASSE } \\
\text { TEXTURAL }\end{array}$} & \multicolumn{2}{|c|}{ DENSIDADE $\left(\mathrm{g} \cdot \mathrm{cm}^{-3}\right)$} \\
\hline argila & silte & areia & & global & partículas \\
\hline 43,16 & 18,72 & 38,12 & argilosa & 1,45 & 2,79 \\
\hline
\end{tabular}


A coleta de dados pluviométricos iniciou-se no dia 06 de dezembro de 2007 e terminou no dia 11 de abril de 2008; para isto, foi utilizado um pluviômetro paulista, instalado a 1,20 m de altura, com $21,1 \mathrm{~cm}$ de diâmetro (área de captação de $350 \mathrm{~cm}^{2}$ ), localizado no centro da área experimental. Os dados de chuva eram coletados logo após o término da mesma. Quando coletados pela manhã, a chuva da manhã somava-se à da noite anterior, e estão apresentados na Tabela 3.

TABELA 3. Chuvas (em mm) durante o experimento. Rainfall (in mm) during the experiment.

\begin{tabular}{|c|c|c|c|c|c|c|c|c|c|}
\hline \multicolumn{2}{|c|}{ dezembro / 07} & \multicolumn{2}{|c|}{ janeiro / 08} & \multicolumn{2}{|c|}{ fevereiro / 08} & \multicolumn{2}{|c|}{ março / 08} & \multicolumn{2}{|c|}{ abril / 08} \\
\hline dia & chuva & dia & chuva & dia & chuva & dia & chuva & dia & chuva \\
\hline 06 & 41,6 & 02 & $91,4 * *$ & 07 & 0,7 & 01 & $16,5^{*}$ & 03 & $15,7^{*}$ \\
\hline 10 & 4,4 & 05 & 1,1 & 08 & $10,1 *$ & 03 & $5,9 *$ & 04 & $23,9 *$ \\
\hline 11 & 25,1 & 06 & $21,8 *$ & 09 & 3,3 & 09 & $33,7 *$ & 07 & $13,7 *$ \\
\hline 14 & $45,7 *$ & 07 & $21,3 *$ & 11 & $25,1 *$ & 11 & 0,3 & 09 & 4,1 \\
\hline 20 & $31,1 *$ & 12 & $46,0^{*}$ & 13 & 0,2 & 12 & $10,1 *$ & 10 & $8,7 *$ \\
\hline 21 & $29,4 *$ & 14 & $17,2 *$ & 17 & 3,3 & 13 & $25,4 *$ & 11 & $52,8 * *$ \\
\hline 26 & 0,8 & 15 & $63,9 * *$ & 18 & 2,6 & 14 & $5,5^{*}$ & total & 119,0 \\
\hline \multirow[t]{9}{*}{ total } & 178,0 & 16 & 4,4 & 19 & 0,2 & 18 & 8,8 & & \\
\hline & & 17 & $31,6^{*}$ & 21 & 1,3 & 22 & $8,6^{*}$ & & \\
\hline & & 20 & $42,4 *$ & 22 & $42,9 *$ & 23 & $22,4 *$ & & \\
\hline & & 21 & $14,9 *$ & 23 & 5,2 & total & 137,0 & & \\
\hline & & 22 & 0,1 & 24 & 2,3 & & & & \\
\hline & & 27 & 5,6 & 25 & $23,0 *$ & & & & \\
\hline & & 29 & $60,4 *$ & total & 120,2 & & & & \\
\hline & & 30 & $21,3 *$ & & & & & & \\
\hline & & total & 443,3 & & & & & & \\
\hline
\end{tabular}

Sendo: * leitura válida e ** leitura perdida devido ao transbordamento da caixa d'água

No período analisado, 51 coletas de chuva foram contabilizadas, mas em apenas 31 ocorreu escoamento superficial, e, em 3 destas, devido ao transbordamento das caixas d'água, as leituras foram perdidas; portanto, somente 28 leituras foram validadas.

\section{RESULTADOS E DISCUSSÃO}

$\mathrm{O}$ volume de água ( $\mathrm{Va}$ ) escoado durante o experimento foi dado pelo volume bruto $(\mathrm{Vb})$ coletado, subtraído do volume de solo (Vs) carreado, sendo o volume bruto (Vb) coletado logo após as precipitações, e o volume de solo (Vs), calculado a partir da massa de solo (Ms) e da densidade das partículas do solo $\left(\rho_{\mathrm{s}}\right)$. O volume de água $(\mathrm{Va})$ escoado em cada parcela é apresentado na Tabela 4. 
TABELA 4. Volume de água (Va) calculado $\left(\mathrm{m}^{3}\right)$, nos tratamentos: terraço com feijão (TF), sulco com feijão (SF), rampa com feijão (RF), terraço com capim (TC), sulco com capim (SC), rampa com capim (RC), terraço com solo nu (TN), sulco com solo nu (SN) e rampa com solo nu (RN), entre 14 de dezembro de 2007 e 10 de abril de 2008. Water volume (Va) calculated $\left(\mathrm{m}^{3}\right)$ in treatments: bean terrace (TF), bean furrow (SF), bean slope (RF), grass terrace (CT), grass furrow (CS), grass slope (RC), bare ground terrace $(\mathrm{TN})$, bare ground furrow $(\mathrm{SN})$ and bare ground slope (RN) between 14 December 2007 and April 10, 2008.

\begin{tabular}{|c|c|c|c|c|}
\hline \multirow[t]{2}{*}{ Tratamentos } & \multicolumn{3}{|c|}{ Blocos } & Totais de \\
\hline & I & II & III & Tratamentos \\
\hline $\mathrm{TF}$ & 2,1284 & 2,4408 & 1,6077 & 6,1769 \\
\hline $\mathrm{TC}$ & 2,4846 & 2,7604 & 1,3234 & 6,5684 \\
\hline $\mathrm{TN}$ & 4,2195 & 3,9783 & 3,9128 & 12,1106 \\
\hline SF & 3,2210 & 2,5095 & 2,7930 & 8,5235 \\
\hline SC & 3,6913 & 2,6255 & 3,0932 & 9,4100 \\
\hline $\mathrm{SN}$ & 5,2578 & 3,9503 & 3,9197 & 13,1278 \\
\hline $\mathrm{RF}$ & 3,8517 & 3,4257 & 3,8438 & 11,1212 \\
\hline $\mathrm{RC}$ & 4,6989 & 3,0575 & 3,3691 & 11,1255 \\
\hline $\mathrm{RN}$ & 5,7770 & 4,8312 & 6,0126 & 16,6208 \\
\hline Totais de Blocos & 35,3302 & 29,5792 & 29,8753 & 94,7847 \\
\hline
\end{tabular}

Na Figura 3, são comparados os volumes de água $\left(\mathrm{m}^{3}\right)$ dos nove tratamentos, no período de 14 de dezembro de 2007 a 10 de abril de 2008.

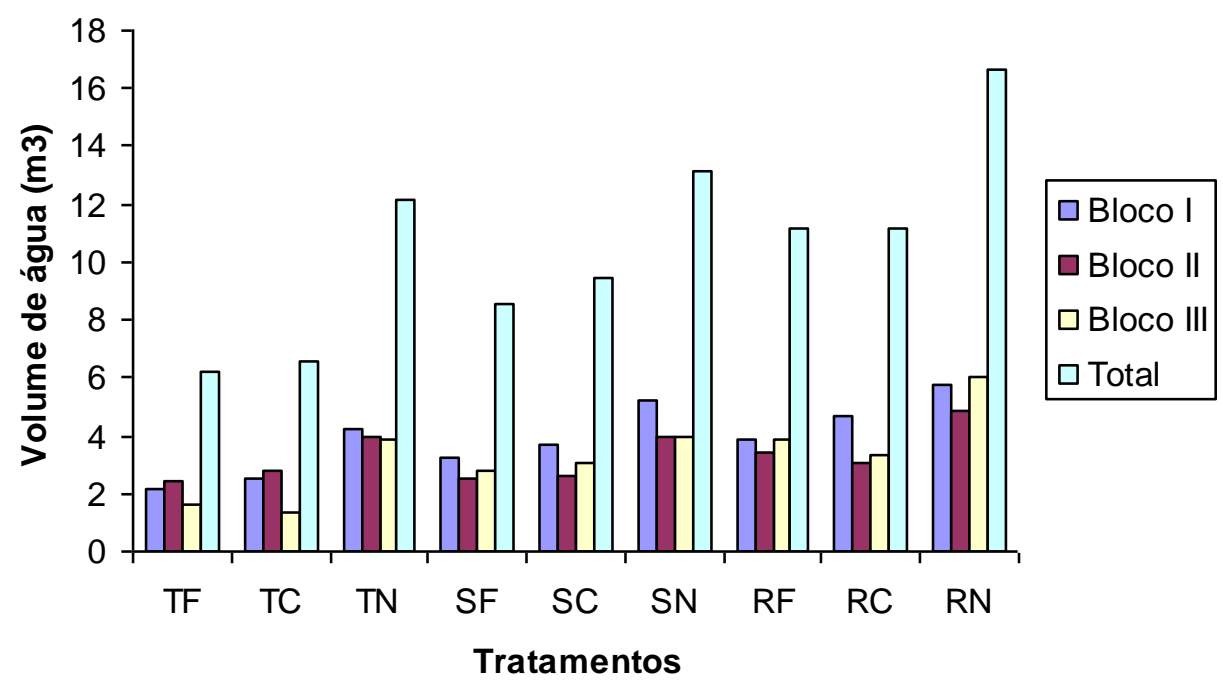

FIGURA 3. Volume de água $\left(\mathrm{m}^{3}\right)$, nos tratamentos: terraço com feijão (TF), terraço com capim (TC), terraço com solo nu (TN), sulco com feijão (SF), sulco com capim (SC), sulco com solo nu ( $\mathrm{SN})$, rampa com feijão $(\mathrm{RF})$, rampa com capim (RC) e rampa com solo nu (RN), entre 14 de dezembro de 2007 e 10 de abril de 2008. Water volume $\left(\mathrm{m}^{3}\right)$ in the treatments: bean terrace (TF),grass terrace (TC), bare ground terrace (TN), bean furrow (SF), grass furrow (SC), bare ground furrow (SN), bean slope (RF), grass slope (RC), bare ground slope (RN) between December 14th, 2007 and April 10th, 2008.

Pôde-se observar pela Figura 3 que o Bloco II apresentou o menor volume de água carreado, isso devendo-se ao fato do bom desenvolvimento das culturas em suas parcelas experimentais. Já o Bloco I apresentou a maior perda de água devido ao desenvolvimento irregular das culturas, e o Bloco III, apesar de obter valores intermediários, apresentou desempenho próximo ao do Bloco II. 
Após a realização da análise de variância, ficou constatado que houve diferença significativa, ao nível de $1 \%$ de probabilidade, entre as estruturas de contenção e entre as coberturas do solo; e não houve diferença significativa, ao nível de $5 \%$ de probabilidade, para a interação (Estrutura $\mathrm{x}$ Cobertura), indicando que a estrutura de contenção independe da cobertura do solo (Tabela 5).

TABELA 5. Análise da variância do efeito das estruturas de contenção nas coberturas do solo em terrenos declivosos, para perdas de água $\left(\mathrm{m}^{3}\right)$. Analysis of Variance of the effect of soil cover and erosion practice on water losses $\left(\mathbf{m}^{3}\right)$.

\begin{tabular}{ccccc}
\hline Causa de & GL & SQ & QM & F \\
Variação & & & 5,4772 & $23,98 * *$ \\
\hline Estruturas (E) & 2 & 10,9544 & 8,82535 & $38,64 * *$ \\
Coberturas (C) & 2 & 17,6507 & 0,096475 & $0,42 \mathrm{~ns}$ \\
Interação (E x C) & 4 & 0,3859 & - & - \\
\hline (Tratamentos) & $(8)$ & $(28,991)$ & - & - \\
Blocos & 2 & 2,3303 & 0,22839 & \\
Resíduo & 16 & 3,6543 & & \\
\hline Total & 26 & 34,9756 &
\end{tabular}

O coeficiente de variação do experimento, na análise de perda de água, foi de 13,61\%, que segundo Ferreira (2000) indica boa precisão experimental.

Para comparação entre médias de estruturas de contenção da enxurrada e médias de coberturas do solo, foi realizado o teste de Tukey, ao nível de $5 \%$ de probabilidade, conforme se verifica na Tabela 6.

TABELA 6. Efeito das estruturas de contenção na reação de coberturas do solo. Médias referentes à perda de água $\left(\mathrm{m}^{3}\right)$. Effect of erosion control practice and soil cover on water losses $\left(\mathbf{m}^{3}\right)$.

\begin{tabular}{ccccc}
\hline Estruturas & Coberturas & Médias de \\
& Feijão & Capim & Solo Nu & Estruturas \\
\hline Terraço & 2,05897 & 2,18947 & 4,03687 & $2,76177 \mathrm{a}$ \\
Sulco & 2,84117 & 3,13667 & 4,37593 & $3,45126 \mathrm{~b}$ \\
Rampa & 3,70707 & 3,70850 & 5,54027 & $4,31861 \mathrm{c}$ \\
\hline Médias de Coberturas & $2,86907 \mathrm{a}$ & $3,01155 \mathrm{a}$ & $4,65102 \mathrm{~b}$ & \\
\hline
\end{tabular}

As médias de coberturas e médias de estruturas com a mesma letra não diferem entre si, pelo teste de Tukey, ao nível de 5\% de probabilidade.

De acordo com o teste de Tukey, ao nível de 5\% de probabilidade, com relação às Estruturas, todas diferiram entre si, sendo o Terraço a estrutura que apresentou a menor perda de água, o Sulco apresentou perda intermediária e a Rampa mostrou a maior perda de água.

Ainda de acordo com o teste de Tukey, ao nível de 5\% de probabilidade, mas com relação às Coberturas, o Feijão, apesar de não diferir estatisticamente do Capim, apresentou a menor perda de água, o Capim obteve perda intermediária e o Solo $\mathrm{Nu}$ diferiu estatisticamente dos dois e apresentou a mais alta perda de água.

O teste de Tukey também foi aplicado para comparar as médias entre tratamentos (Tabela 7).

As médias de tratamentos com a mesma letra não diferem entre si, pelo teste de Tukey, ao nível de $5 \%$ de probabilidade.

De acordo com o teste de Tukey, ao nível de 5\% de probabilidade, com relação aos tratamentos, o tratamento Terraço-Feijão, apesar de não diferir estatisticamente do tratamento 
Terraço-Capim, apresentou a menor perda de água; o tratamento Rampa-Solo $\mathrm{Nu}$ diferiu estatisticamente de todos e foi o que apresentou a mais alta perda de água; os tratamentos Sulco-Feijão, Sulco-Capim, Rampa-Feijão e Rampa-Capim apresentaram valores intermediários, e os tratamentos Terraço-Solo Nu e Sulco-Solo Nu não diferiram entre si e só foram mais eficientes que a Rampa Solo-Nu.

TABELA 7. Comparação entre as Perdas Médias de Água $\left(\mathrm{m}^{3}\right)$ para os nove tratamentos. Comparison between the averages of water losses $\left(\mathrm{m}^{3}\right)$ for the nine treatments.

\begin{tabular}{ccccc}
\hline Tratamentos & I & Blocos & II & $\begin{array}{c}\text { Médias de } \\
\text { Tratamentos }\end{array}$ \\
\hline Terraço Feijão & 2,1284 & 2,4408 & 1,6077 & $2,05897 \mathrm{a}$ \\
Terraço Capim & 2,4846 & 2,7604 & 1,3234 & $2,18947 \mathrm{a}$ \\
Sulco Feijão & 3,2210 & 2,5095 & 2,7930 & $2,84117 \mathrm{~b}$ \\
Sulco Capim & 3,6913 & 2,6255 & 3,0932 & $3,13667 \mathrm{bc}$ \\
Rampa Feijão & 3,8517 & 3,4257 & 3,8438 & $3,70707 \mathrm{~cd}$ \\
Rampa Capim & 4,6989 & 3,0575 & 3,3691 & $3,70850 \mathrm{~cd}$ \\
Terraço Solo Nu & 4,2195 & 3,9783 & 3,9128 & $4,03687 \mathrm{de}$ \\
Sulco Solo Nu & 5,2578 & 3,9503 & 3,9197 & $4,37593 \mathrm{e}$ \\
Rampa Solo Nu & 5,7770 & 4,8312 & 6,0126 & $5,54027 \mathrm{f}$ \\
\hline
\end{tabular}

$\mathrm{Na}$ Figura 4, são comparadas as perdas médias de água $\left(\mathrm{m}^{3}\right)$ dos nove tratamentos, no período de 14 de dezembro de 2007 a 10 de abril de 2008.

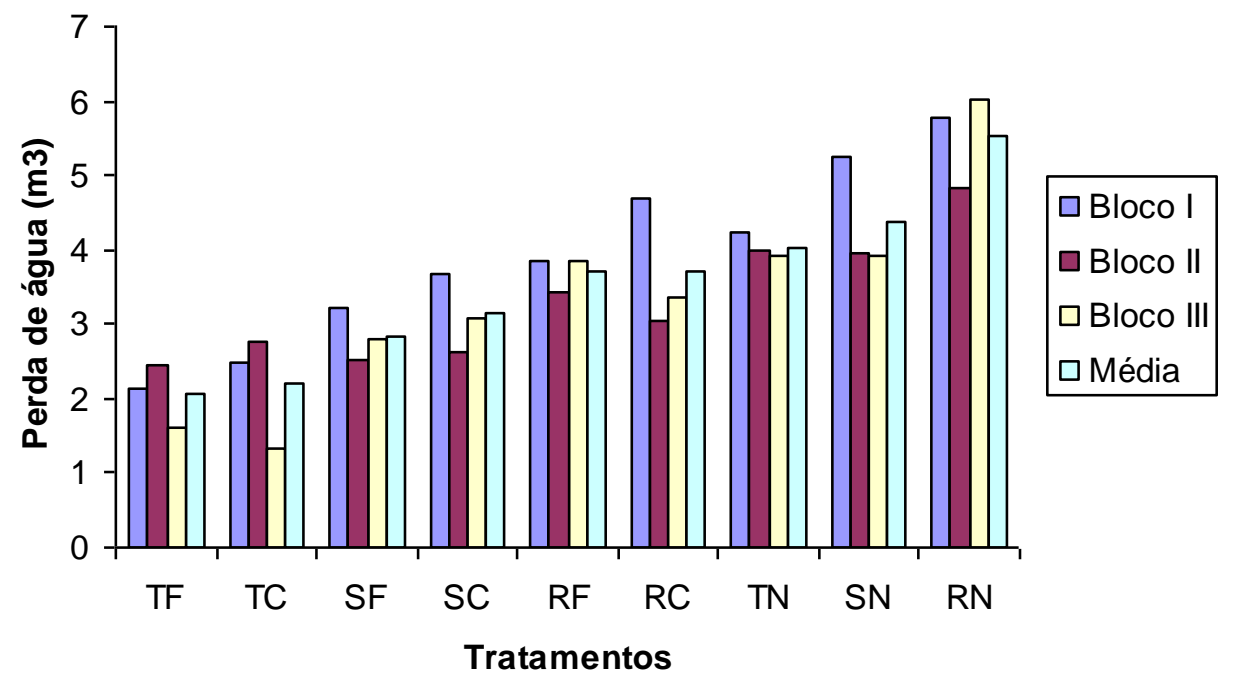

FIGURA 4. Perda média de água $\left(\mathrm{m}^{3}\right)$, nos tratamentos: terraço com feijão $(\mathrm{TF})$, terraço com capim (TC), sulco com feijão (SF), sulco com capim (SC), rampa com feijão (RF), rampa com capim (RC), terraço com solo nu (TN), sulco com solo nu (SN) e rampa com solo nu (RN), entre 14 de dezembro de 2007 e 10 de abril de 2008. Average water loss $(\mathrm{m} 3)$ in the treatments: bean terrace (TF), grass terrace (TC), bean furrow (SF), grass furrow (SC), bean slope (RF), grass slope (RC), bare ground terrace (TN), bare ground furrow (SN) bare ground slope (RN) between December 14th, 2007 and April 10th, 2008.

A perda média de água apresentada na Tabela 7 é referente a uma parcela de $18 \mathrm{~m}^{2}(12 \times 1,5$ $\mathrm{m})$; para uma área de um hectare, temos as seguintes perdas médias de água: $1.143,9 \mathrm{~m}^{3}, 1.216,4$ $\mathrm{m}^{3}, 1.578,4 \mathrm{~m}^{3}, 1.742,6 \mathrm{~m}^{3}, 2.059,5 \mathrm{~m}^{3}, 2.060,3 \mathrm{~m}^{3}, 2.242,7 \mathrm{~m}^{3}, 2.431,1 \mathrm{~m}^{3}$ e $3.077,9 \mathrm{~m}^{3}$, para os respectivos tratamentos: Terraço-Feijão, Terraço-Capim, Sulco-Feijão, Sulco-Capim, Rampa-Feijão, Rampa-Capim, Terraço-Solo Nu, Sulco-Solo Nu e Rampa-Solo Nu. 
Em estudo realizado na cultura do milho BR catingueiro com parcelas experimentais de 10,0 $\mathrm{m}$ x 5,0 m, BRITO et al. (2008) coletaram uma precipitação pluviométrica de 322,8 $\mathrm{mm}$ ao longo do ciclo da cultura e obtiveram volumes de água escoada de: $6.089 \mathrm{~L}, 2.976 \mathrm{~L}, 3.285,5 \mathrm{~L}, 1.066 \mathrm{~L} \mathrm{e}$ 4.811 L, para os respectivos tratamentos: Guimarães Duque, aração profunda, aração parcial, sulcos barrados e sistema tradicional (sem preparo do solo).

Avaliações da eficiência do "mulching" vertical para o manejo de enxurrada, em um solo Podzólico Vermelho-Amarelo, em Santa Maria-RS, evidenciaram que a adoção dessa técnica conservacionista reduziu em 52\% a taxa do escoamento superficial (NISHIJIMA \& RIGHES, 1987).

A utilização do vertical mulching em Latossolo Vermelho distrófico típico, em semeadura direta, reduz o escoamento superficial de água no solo em até 48,66\%, com espaçamento de $10 \mathrm{~m}$ entre sulcos, e em até 54,54\% com espaçamento de $5 \mathrm{~m}$, em relação ao mesmo sistema, sem vertical mulching (GARCIA \& RIGHES, 2008).

Margolis et al. (1985), avaliando o efeito de diferentes tipos de cobertura vegetal sobre as perdas por erosão, constataram que a palma forrageira cultivada em morro abaixo, num solo Litólico de Caruaru - PE, aumentou a perda de água, na ordem de 36,0 mm. ano ${ }^{-1}$ em relação ao plantio em nível.

O uso do "mulching" vertical, em sistema plantio direto, em um Latossolo Vermelho distrófico típico, reduz as perdas de água por escoamento superficial entre 49,6 e 67,1\%, em função do espaçamento entre os sulcos com "mulching" e das intensidades de chuva (COSTA, 2004).

A aplicação do "mulching" vertical em sistema plantio direto reduz o escoamento superficial de água no solo em 48,66 e 54,54\%, respectivamente, com "mulching" vertical a cada 10 e a cada 5 metros, em comparação ao sistema plantio direto sem "mulching" vertical (HERBES, 2003).

Em trabalho conduzido durante sete anos por Dechen e Prochnow (2003), demonstrou-se que $20 \%$ da precipitação pluvial total foi perdida com a enxurrada no solo mantido totalmente descoberto.

\section{CONCLUSÕES}

Não houve interação entre Coberturas do solo e Práticas de Controle de Erosão.

Observando as perdas de água, o Terraço foi o que obteve o menor escoamento superficial, a Rampa desenvolveu o maior escoamento e o Sulco teve desempenho intermediário. O Feijão foi a cultura que segurou mais água no solo, seguido pelo Capim e por último o Solo $\mathrm{Nu}$.

Devido ao replantio do feijão, houve maior movimentação de terra nas parcelas com esta cobertura de solo, favorecendo assim maior infiltração de água.

\section{AGRADECIMENTOS}

À CAPES e ao INCTEI, pelo apoio a esta pesquisa.

\section{REFERÊNCIAS}

BRITO, L. T. L.; CAVALCANTI, N. B.; ANJOS, J. B. dos; SILVA, A. S.; PEREIRA, L. A. Perdas de solo e de água em sistemas de captação in situ no Semi-Árido brasileiro. Engenharia Agrícola, Jaboticabal, v. 28, n. 3, p. 507 515. 2008.

COSTA, R.D. Nutrientes na água do escoamento superficial em sistema plantio direto com mulching vertical. 2004. 63 f. Dissertação (Mestrado em Engenharia Agrícola)-Universidade Federal de Santa Maria, Santa Maria, 2004.

DECHEN, S.C.F.; PROCHNOW, D. Erosão e produtividade. O Agronômico, Campinas, v. 55, n. 1, p. 22-24, 2003. 
FERREIRA, P.V. Estatística experimental aplicada à agronomia. 3. ed. Maceió: EDUFAL, 2000. $422 \mathrm{p}$.

GARCIA, S. M.; RIGHES, A. A. Vertical Mulching e manejo da água em semeadura direta. Revista Brasileira de Ciência do Solo, Viçosa, v..32 n.2, p. 833-842, 2008.

GOMES, F. P. Curso de estatística experimental. 13. ed. São Paulo: Nobel, 1990. 468p.

HERBES, M.G. Escoamento superficial em sistema plantio direto com mulching vertical. 2003. 94 f. Dissertação (Mestrado em Engenharia Agrícola)-Universidade Federal de Santa Maria, Santa Maria, 2003.

LIBARDI, P.L. Dinâmica da água no solo. São Paulo: EDUSP, 2005. v. 1, 344 p.

MARGOLIS, E.; SILVA, A.B. da; JACQUES, F.O. Determinação dos fatores da equação universal de perda de solo para as condições de Caruaru-PE. Revista Brasileira de Ciência do Solo, Viçosa, v. 9, p. 165-169, 1985.

MARTINS FILHO, M. V. et al. Perdas de solo e nutrientes por erosão num Argissolo com resíduos vegetais de cana-de-açúcar. Engenharia Agrícola, Jaboticabal, 2009, v.29, n.1, p. 8-18.

MELLO, C.R.; SÁ, M.A.C.; CURI, N.; MELLO, J.M.; VIOLA, M.R.; SILVA, A.M. Erosividade mensal e anual da chuva no Estado de Minas Gerais. Pesquisa Agropecuária Brasileira, Brasília, v. 42, p. 537-545, 2007.

MOREIRA, M.C.; CECÍLIO, R.A.; PINTO, F.A.C.; PRUSKI, F.F. Desenvolvimento e análise de uma rede neural artificial para estimativa da erosividade da chuva para o Estado de São Paulo. Revista Brasileira de Ciência do Solo, Viçosa, v.30, p.1.069-1.074, 2006.

NISHIJIMA, T.; RIGHES, A.A. Escoamento superficial de água em cinco sistemas de manejo do solo com cultura do milho. Ciência Rural, Santa Maria, v. 17, n. 3, p. 223-233, 1987.

SANTOS, G.G.; NORI, P.G.; OLIVEIRA, LF.C. Chuvas intensas relacionadas à erosão hídrica. Revista Brasileira de Engenharia Agrícola e Ambiental, Campina Grande, v. 14, n.2, p.115-123, 2010.

SILVEIRA, R.C. Estudo de perdas de solo e água, sob diferentes níveis de resíduos culturais de milho, usando um simulador de chuvas. 1998. 52 p. Dissertação (Mestrado em Engenharia Agrícola)- Universidade Federal de Lavras, Lavras, 1998. 